\title{
Duodenal lipoma - Report of two cases and review of the
} literature

\author{
JerEmy GOLDBERG, MB, ChB, STEWART M HAMILTON, MD, FRCSC, RD CHERRY, MD, FRCPC, \\ RW SHERBANIUK, MD, FRCPC, LAURENCE D JEWELL, MD, FRCPC
}

\begin{abstract}
Diagnostic upper gastrointestinal endoscopy has increased the frequency with which duodenal lipomas are encountered in clinical practice. Although the smaller lesions are usually incidental endoscopic findings unrelated to symptoms, an accurate diagnosis depends upon biopsy and histological assessment. Larger lesions may bleed or obstruct. The authors present two cases: one lipoma was found incidentally during the investigation of an esophageal motility disorder; the other larger one presented as a mass lesion in a patient with upper gastrointestinal bleeding. Pathological findings suggested that the lipoma was the cause of the bleeding. Management is briefly discussed. Can J Gastroenterol $1990 ; 4(4): 147-150$
\end{abstract}

Key Words: Duodenum, Endoscopy, Lipoma, Polyp

\section{Lipome duodénal: Rapport de deux cas et revue de la littérature}

RESUME: L'endoscopie diagnostique des voies digestives supérieures a augmenté la fréquence avec laquelle on découvre les lipomes du duodénum en cours de pratique clinique. Bien que les lésions plus petites soient habituellement des résultats endoscopiques secondaires qui ne sont pas reliés aux symptômes du patient, un diagnostic exact s'appuie sur une démarche biopsique et une évaluation histologique. Il est possible que les lésions plus importantes saignent ou deviennent obstructives. Les auteurs rapportent deux cas: le premier lipome a été découvert fortuitement au cours d'un examen effectué suite à des troubles de la motilité de l'oesophage; le second, plus volumineux, se présentait comme une lésion expansive chez un patient souffrant de saignement gastrointestinal. Les résultats pathologiques suggèrent que le lipome était à l'origine de ce saignement. Le traitement est rapidement examiné.

Departments of Pathology, Surgery, and Medicine (Gastroenterology), University of Alberta, Edmonton, Alberta

Correspondence and reprints: Dr Laurence D Jewell, Department of Pathology, University of Alberta, 5B4.12 Walter C Mackenzie Health Sciences Centre, Edmonton, Alberta T6G 2R7.

Telephone (403) 492-8990

Received for publication July 31, 1989. Accepted December 12, 1989
D UODENAL POLYPS ARE RARE, AND before the advent of widespread upper gastrointestinal endoscopy, they were usually regarded as pathological curiosities of no clinical significance. Small lesions may be encountered as incidental endoscopic findings. Larger lesions are more likely to bleed or obstruct. Precise diagnosis depends upon biopsy and histological assessment. Adenomas are the most common of the mucosal lesions and have definite malignant potential. A variety of submucosal lesions, mostly benign, also occur. Tumours of fatty tissue are among the most common of these and are the subject of this report.

\section{CASE ONE}

A 71-year-old female retired nurse presented with dysphagia of two years' duration. The symptoms dated back to the time of previous surgery and radiation for thyroid lymphoma and were most noticeable when she swallowed liquids.

Her appetite had decreased; however weight was steady at $145 \mathrm{lbs}$ (66 $\mathrm{kg}$ ). She denied nausea or vomiting, nor were there problems with bowel habit. Her medications included replacement thyroxine and intermittent triazolam. The patient denied any allergies. 


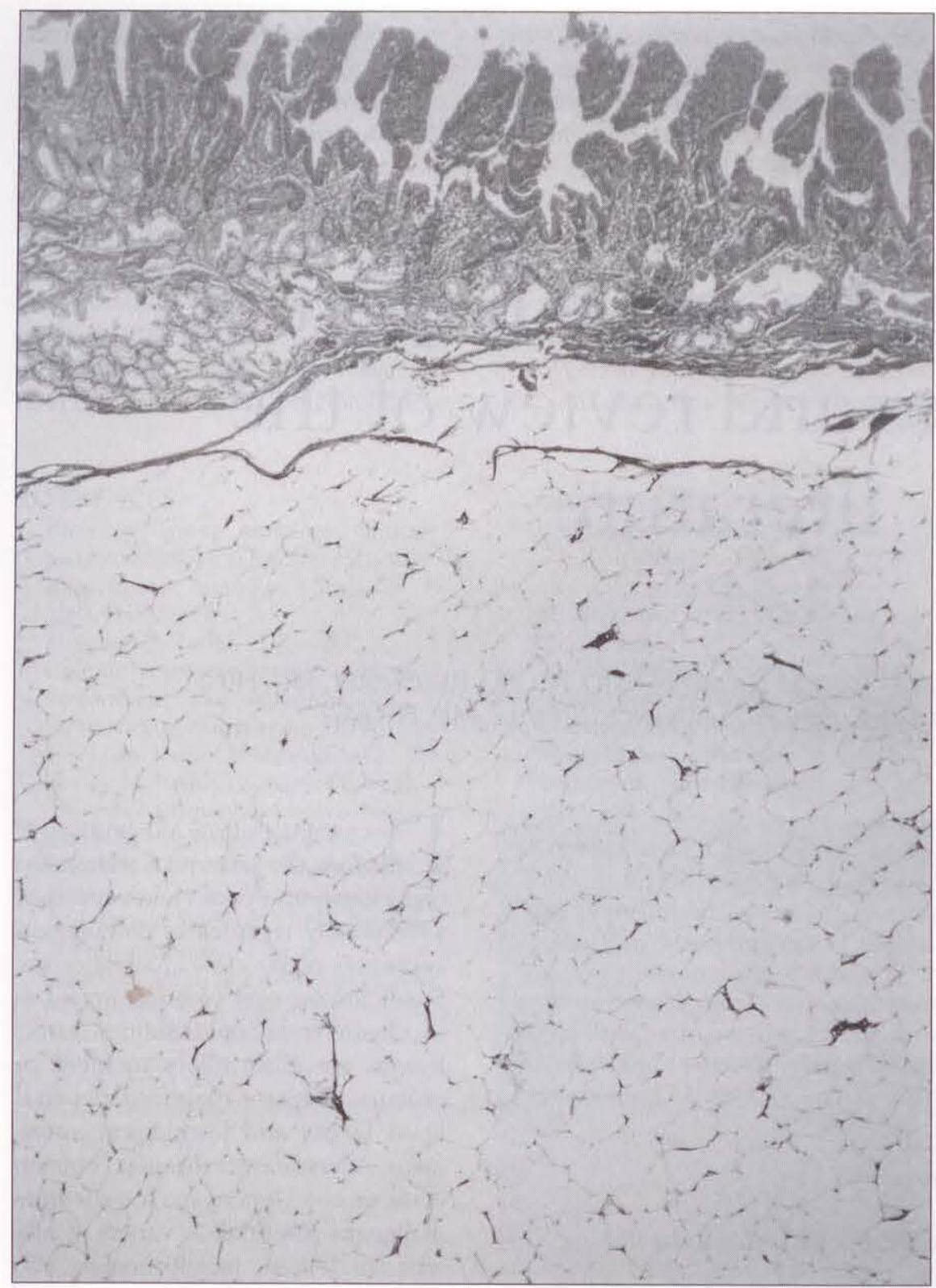

Figure 1) Mature adipose tissue is identified in the submucosa of this duodenal biopsy. The overlying mucosa is entirely normal. (Hematoxylin and eosin $\times 13.3$ )

Physical examination was unremarkable except for diminished olfactory gustatory activity since the time of radiation. After routine premedication, an Olympus XZ endoscope was easily passed into the esophagus. The gastric mucosa and pylorus were normal. On entering the duodenum a smooth oval polyp measuring $2 \mathrm{~cm}$ in diameter was noted; biopsies were taken.

Histopathological sections confirmed the presence of a submucosal lipoma with normal overlying duodenal mucosa (Figure 1). The patient did well postoperatively. The polyp was sub- sequently removed by snare and cautery and the patient is presently asymptomatic.

\section{CASE TWO}

A 68-year-old male, a nonsmoker and social drinker with a longstanding history of peptic ulcer disease, presented with an acute episode of hematemesis. At the time he had been taking nonsteroidal anti-inflammatory drugs for arthralgia. There had been three previous episodes of upper gastrointestinal bleeding over the preceding 20 years which had been managed conservatively.
The patient was admitted to a rural hospital and transfused with three units of blood. Upper gastrointestinal series demonstrated a polypoid mass at the duodenal apex (Figure 2). Having made a rapid recovery he was discharged on cimetidine and referred for endoscopy.

Physical examination revealed a 68 . year-old male in apparent good health. The abdomen was soft, nontender, with no clinical evidence of organomegaly. Rectal examination was unremarkable.

After the routine premedication, the patient underwent endoscopy. The esophagus, cardia, fundus and main body of the stomach were grossly normal. In the antrum a possible scar from previous APD ulcer was seen. The scope was intubated into the duodenum, and the polyp, which was extremely mobile, was detected with some difficulty. Biopsies revealed normal duodenal mucosa.

The patient was subsequently re-admitted for investigation and more definitive treatment. A hypotonic duodenogram performed revealed a polypoid lesion in the first part of the duodenum.

In view of the history of hemat. emesis and the lack of a histological diagnosis, excision of the lesion was deemed necessary. The polyp was relatively broad-based and not amenable to endoscopic removal with snare and cautery; hence, the patient underwent a duodenotomy with local excision of the tumour.

Gross examination showed the mass to be a $2 \times 1 \mathrm{~cm}^{2}$ submucosal duodenal lipomatous polyp. The overlying mucosa showed a healing ulceration (Figure 3 ), suggesting that this lesion had been the source of the recent bleed. ing.

The patient made an uneventful postoperative recovery and is presently asymptomatic.

\section{DISCUSSION}

The incidence of gastrointestinal tract tumours within the small bowel ranges from 0.5 to $6 \%(1,2)$. While comprising $8 \%$ of the small bowel by length, the duodenum harbours 10 to $22 \%$ of small intestinal tumours $(3,4)$. Mayo and Smith (5) reported an in- 


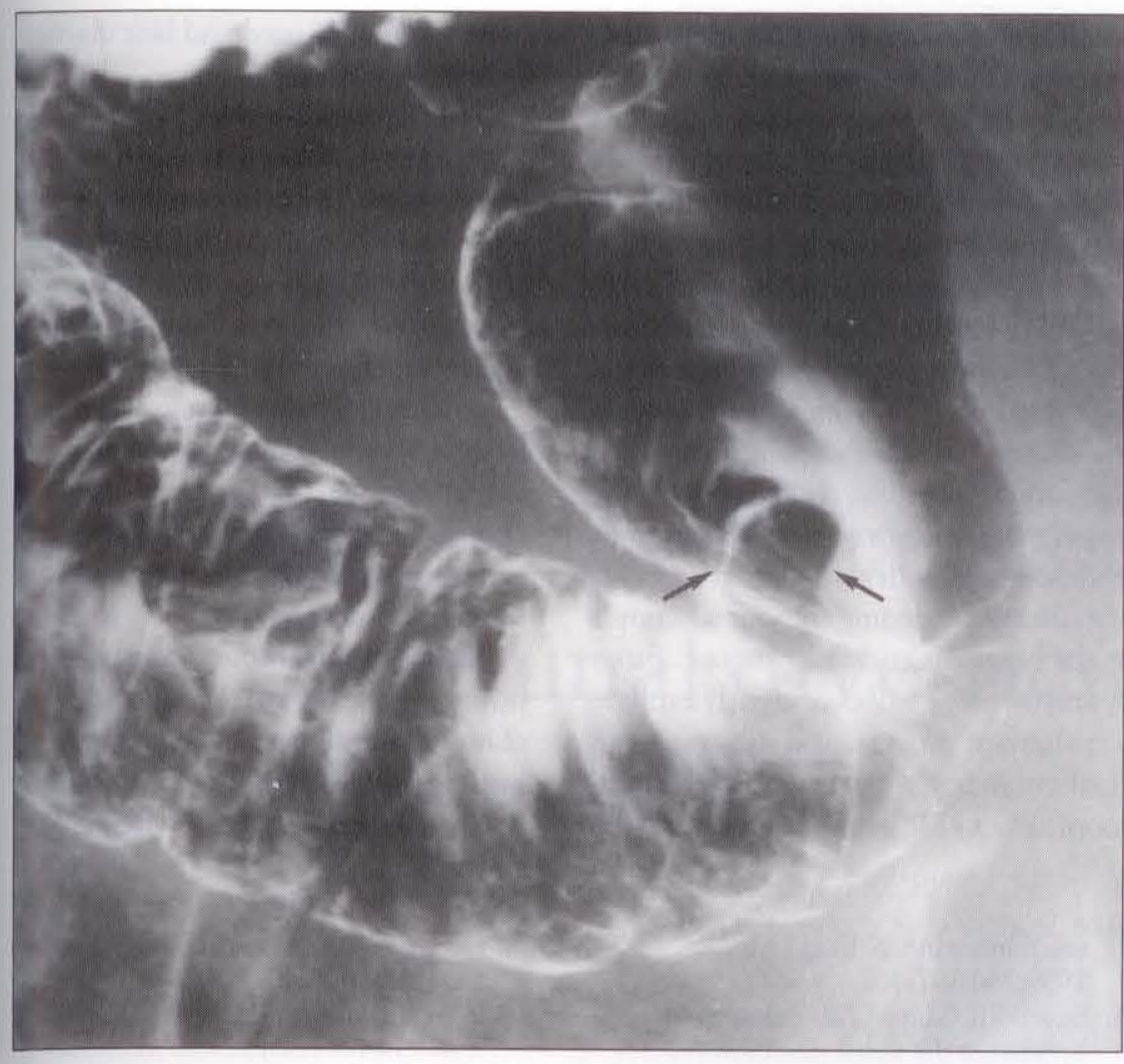

Figure 2) A polypoid lesion is visualized by hypotonic duodenography. The lesion is seen in the first part of the duodenum (arrows)

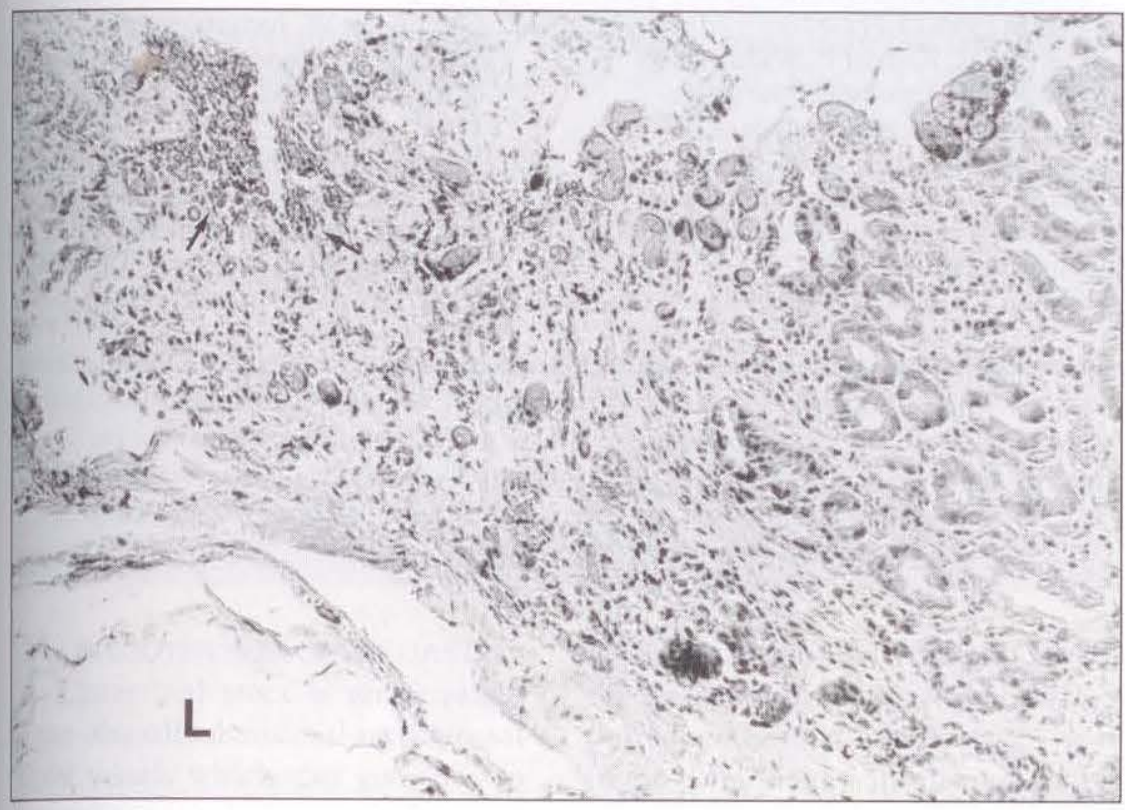

Figure 3) The mucosa overlying the lipoma ( $L$ ) shows an area of erosion, with zones of both healing and active hemorrhage (arrows). (Hematoxylin and eosin $\times 27$ )

cidence of subclinical lipomas in one of 325 autopsies performed $(0.3 \%)$. Weinberg and Feldman (6) studied 1319 autopsies with a lipoma incidence of $5.8 \%$. After the colon, the small intestine was the second most common loca- tion for lipomas within the gastrointestinal tract. This is supported by Hurwitz et al (7), whose study of 72 lipomas was distributed as follows: esophagus $2.8 \%$, stomach $8.3 \%$, small bowel $25 \%$, and colon $46 \%$. Within the small intestine lipomas occur most often in the ileum, followed by the duodenum and jejunum (5). In most series lipomas are the second most common benign small bowel neoplasm (first are smooth muscle tumours) $(1,8)$. Lipomas are commonly noted between the fifth and seventh decade and are distributed more or less evenly between sexes $(6,7)$. The etiology remains controversial. They are thought to have the same origin as normal fat tissue, while those arising in areas where adipose tissue does not normally exist are believed to arise from embryonically misplaced adipose tissue (6). Within the gastrointestinal tract a lipoma is usually located in the submucosa, although the subserosa may also be involved (7). In addition to the more usual solitary lipoma, a rare diffuse hamartomatous form occurs (9). The tumour is generally surrounded by a capsule (6), and the cut surface has a yellow lobulated appearance. The growth may be sessile or pedunculated and size varies from 0.5 $\mathrm{cm}$ in diameter to $14 \times 8 \times 5 \mathrm{~cm}^{3}$. The average size is about $4 \mathrm{~cm}$ in diameter. The tumour may undergo hemorrhage, necrosis, cystic degeneration, calcification, or even sloughing. Malignant change has not been reported (1). Histologically lipomas consist of well differentiated adipose tissue separated by connective tissue septa.

Lipomas are benign and small and therefore usually detected coincidentally (ie, at surgery or during investigations for other gastrointestinal complaints). When symptoms are present they usually relate to a complication - either obstruction (4) or hemorrhage (10).

Lesions of the proximal small bowel have a tendency to produce nausea, vomiting and epigastric pain while distal tumours are more commonly associated with periumbilical crampy pain, borborygmus, distension and vomiting. Intussusception is more likely to be associated with a benign pedunculated tumour (4).

Bleeding may be acute, presenting as hematemesis, or occult, leading to iron deficiency anemia. It is usually caused by superficial ulceration of the overlying mucosa. 
The clinical findings on examination are nonspecific unless related to one of the above-mentioned complications. The finding of a palpable abdominal mass usually suggests malignant disease.

While a definite diagnosis cannot always be made radiographically, certain features are often present which alert the radiologist to the likelihood of a small bowel lipoma. The barium contrast study is the best radiological means of establishing a diagnosis. Computed tomography scan may demonstrate attenuation values consistent with fat.

Because of its soft consistency, the lipoma is pliable and can be seen to change shape when palpated or squeezed by peristalsis (1). A solitary intraluminal defect that conforms to the shape of the

\section{REFERENCES}

1. Olmsted W, Ros PR, Hjermstad BM, McCarthy MJ, Dachman AH. Tumors of the small intestine with little or no malignant predisposition: A review of the literature and a report of 56 cases. Gastrointest Radiol 1987;12:231-9.

2. Gupta S, Gupta S. Primary tumors of the smallyowel. A clinicopathological study of 58 cases. J Surg Oncol 1982;20:161-7.

3. Reddy R, Schuman BM, Priest RJ. Duodenal polyps: Diagnosis and management. J Clin Gastroenterol 1981;3:139-45.

4. Darling RC, Welch CE. Tumors of the small bowel lumen is usually identified. Fractional small bowel passage of contrast at half hourly intervals until it reaches the ileocecal valve may identify filling defects, mucosal distortions, extrinsic pressure deformities, obstruction and intussusception when studied carefully $(1,2,4,8,11)$. During active hemorrhage, angiography may reveal a bleeding lesion (10). Flexible fibreoptic endoscopy has made visualization of the duodenum possible. In patients with upper gastrointestinal bleeding, prompt endoscopy provides the opportunity for visualizing a bleeding tumour when it is in the range of the duodenoscope. Biopsy and cytology will confidently exclude a malignant process, and in some cases the benign polyp can be removed endoscopically (12). The endoscope is the

small intestine. N Engl J Med 1959;260:397-407.

5. Smith FR, Mayo CW. Submucous lipomas of the small intestine. Am J Surg 1950;80:920-8.

6. Weinberg T, Feldman M Sr. Lipomas of the gastrointestinal tract. Am J Clin Pathol 1955;25:272-81.

7. Hurwitz M, Redleaf P, Williams HJ, Edwards JE. Lipomas of the gastrointestinal tract. An analysis of 72 tumors. Am J Radiol 1967;99:84-9.

8. Schier J. Diagnostic and therapeutic aspects of tumors of the small bowel. Int Surg 1972;57:789-92.

9. Climie ARW, Wylin RF. Small most frequently used and best diagnostic investigation.

Most lipomas less than $1 \mathrm{~cm}$ in size are asymptomatic and do not require excision if endoscopic biopsy is consistent with a benign submucosal process (3). Obtaining an adequate biopsy from an extremely mobile or deep-seated lesion can be difficult and may often yield normal duodenal mucosa, as illustrated by case 2 . Pedunculated lesions, accessible to the duodenoscope, can be removed by snare and cautery, while lesions inaccessible to diag. nosis are best removed by enterotomy and local resection as in case 2 .

If the lipoma is complicated by hemorrhage it should be excised. In the case of intussusception, resection of the entire intussuscepted mass may be necessary when attempted reduction fails (10).

intestinal lipomatosis. Arch Pathol Lab Med 1981;105:40-2.

10. Weiss A, Mollura JL, Profy A, Cohen R. Two cases of complicated intestinal lipoma. Review of small intestinal lipomas. Am J Gastroenterol 1979;72:83-8.

11. Ostermiller W, Joergenson EJ, Weibel L. A clinical review of tumors of the small bowel. Am J Surg 1966;3:403-9.

12. Wald A, Milligan FD. The role of fiberoptic endoscopy in the diagnosis and management of duodenal neoplasms. Am J Dig Dis 1975;20:499. 505 . 


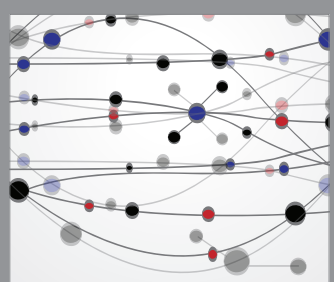

The Scientific World Journal
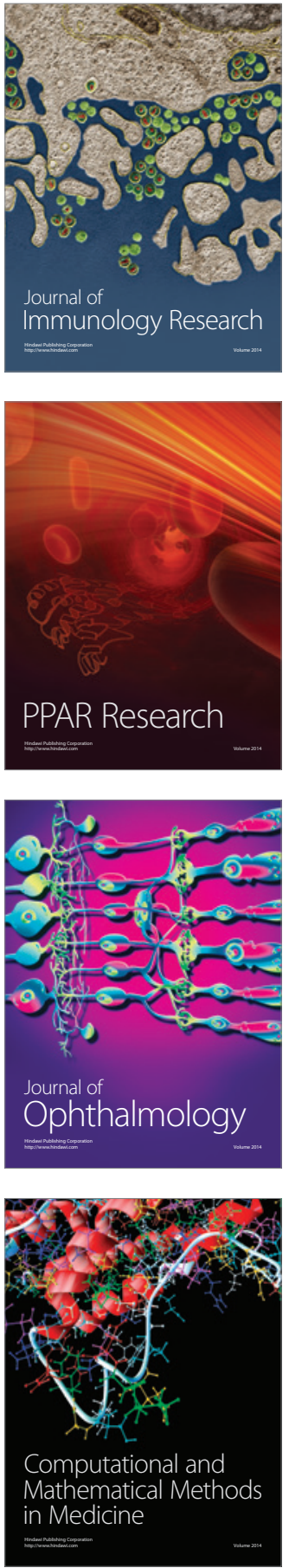

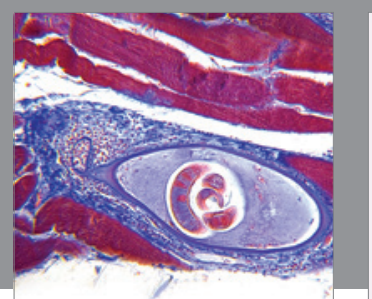

Gastroenterology Research and Practice

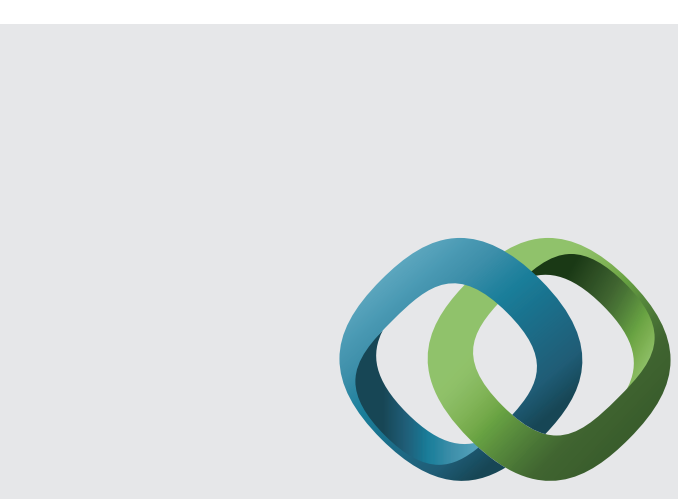

\section{Hindawi}

Submit your manuscripts at

http://www.hindawi.com
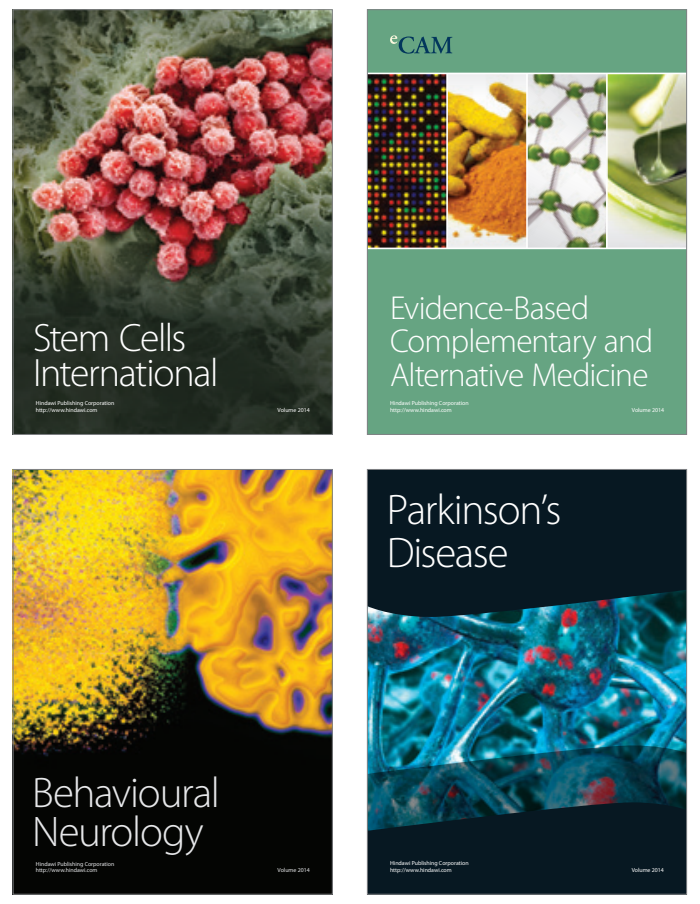
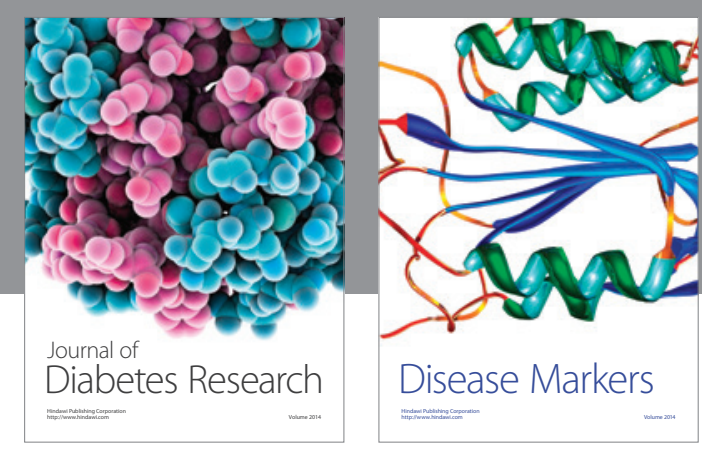

Disease Markers
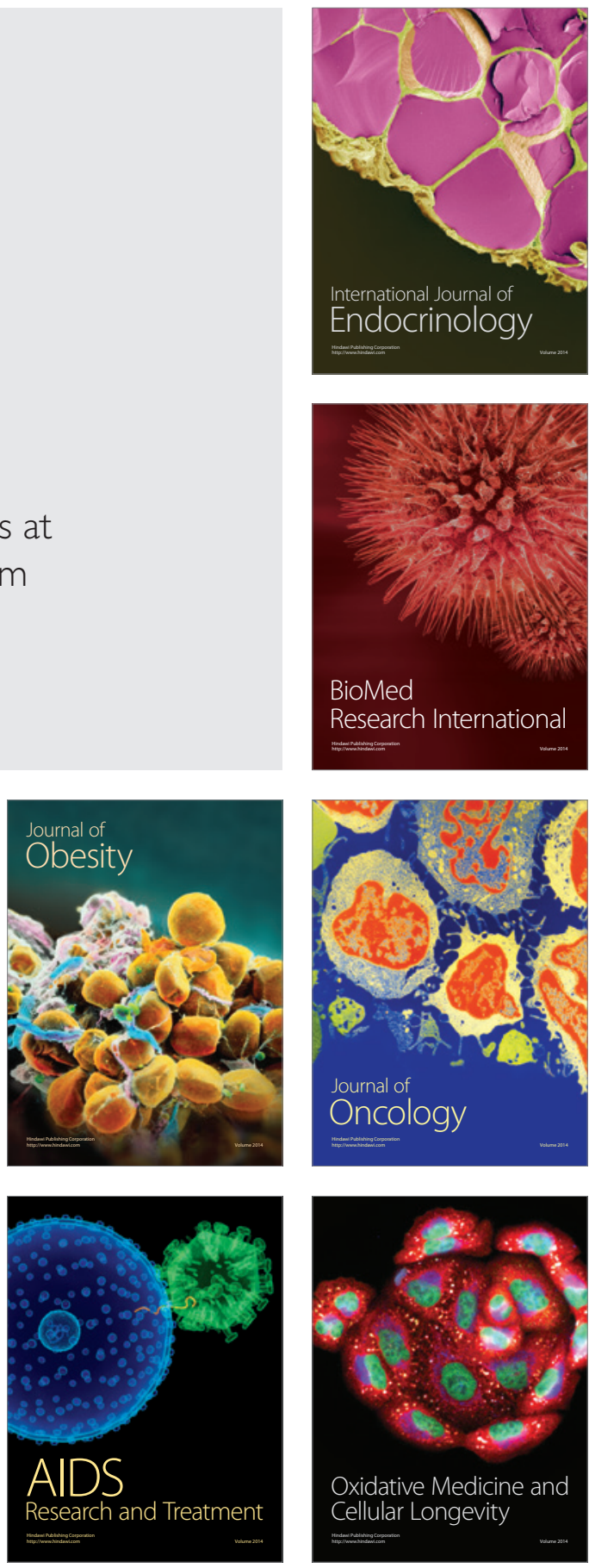